\title{
Factors Associated with the Remission of Type 1 Diastolic Dysfunction after Dapagliflozin Treatment in Patients with Type 2 Diabetes
}

\author{
Adina Braha ${ }^{1}{ }^{1}$, Alin Albai ${ }^{1, *}$, Romulus Timar ${ }^{1}$, Laura Diaconu ${ }^{1}$, Lucian Vasiluță ${ }^{1}$, \\ Daniela Cipu ${ }^{2}$, Bogdan Timar ${ }^{1}$ and Alexandra Sima ${ }^{1}$ \\ 1 Second Department of Internal Medicine, “Victor Babeș” University of Medicine and Pharmacy, \\ 300041 Timisoara, Romania; braha.adina@umft.ro (A.B.); timar.romulus@umft.ro (R.T.); \\ diaconu.laura@umft.ro (L.D.); l.vasiluta@yahoo.com (L.V.); bogdan.timar@umft.ro (B.T.); \\ alexa_moisuc@yahoo.com (A.S.) \\ 2 Department of Orthopedics-Traumatology, Urology and Medical Imaging, "Victor Babeș” University of \\ Medicine and Pharmacy, 300041 Timisoara, Romania; danscipu@yahoo.com \\ * Correspondence: alin_albai@yahoo.com
}

Received: 31 October 2020; Accepted: 21 November 2020; Published: 23 November 2020

\begin{abstract}
Patients with type 2 diabetes (T2DM) are at high risk of developing cardiovascular disease and heart failure (HF), both with preserved and reduced ejection fraction of the left ventricle. Previous research demonstrated that dapagliflozin treatment is associated with the remission of type 1 diastolic dysfunction (DD1) in patients with T2DM. The main aim of this study was to evaluate the possible baseline predictors associated with the remission of DD1 in patients with T2D after one year of dapagliflozin treatment. In this prospective and observational study, 45 patients with T2DM were evaluated before and after one year of treatment with $10 \mathrm{mg}$ dapagliflozin daily added to their background therapy. In the studied group, 73.3\% (33/45) of the patients had DD1 at baseline. The primary outcome of this research was DD1 remission. DD1 remission was associated with improvement of liver stiffness, an increase in estimated glomerular filtration rate (eGFR), and a decrease in hemoglobin $\mathrm{A} 1 \mathrm{c}(\mathrm{HbA} 1 \mathrm{c})$. Independent predictors for the remission of DD1 were a more than $0.4 \mathrm{kPa}$ difference in the initial stiffness score and the 1-year assessment fibrosis score and a duration of diabetes $\leq 8$ years. Age, body mass index (BMI), or patient weight after one year did not influence the DD1 outcome. Patients with a T2DM duration of less than eight years have the additional benefit of DD1 remission associated with dapagliflozin treatment beyond the conventional benefits such as improvements in glycemic control, cardiovascular, renal, and hepatic risk reductions. In patients with $\mathrm{T} 2 \mathrm{DM}$, the remission of DD1 was associated with decrease of liver stiffness.
\end{abstract}

Keywords: type 1 diastolic dysfunction; dapagliflozin; heart failure; liver steatosis; liver fibrosis

\section{Introduction}

Diabetes mellitus (DM) is a significant risk factor for developing cardiovascular disease, which is the leading cause of death among patients with diabetes [1], and an independent cause for heart failure (HF) even in the absence of coronary atherosclerosis, hypertension, or other conditions traditionally associated with HF [2,3]. HF is a syndrome characterized by non-specific and various clinical signs, which makes the management of this disease a challenge in terms of early diagnosis and treatment.

The diastolic dysfunction of the left ventricle is a pathological condition preceding left HF, often asymptomatic and insufficiently diagnosed, characterized by altered relaxation and compliance of the left ventricular myocardium [4]. In type 1 diastolic dysfunction (DD1), impaired relaxation of the left ventricle is found; in contrast to other grades of diastolic dysfunction, DD1 is reversible [5]. 
Previous research demonstrated that left ventricular diastolic dysfunction is a strong predictor for cardiovascular outcome, even in patients with reduced ejection fraction $[6,7]$.

From a historical perspective, for several decades, the pharmacotherapy of T2DM was focused on reducing blood glucose, based on the idea that intensive glycemic control will bring micro- and macrovascular benefits. Large clinical trials demonstrated a link between glycemic control (evaluated by glycated hemoglobin- $\mathrm{HbA1c}$ ) and the incidence of chronic complications of diabetes, highlighting the beneficial effect of strict glycemic control on microvascular complications [8]. However, strict glycemic control was not consistently associated with a decrease in the incidence of major cardiovascular events or with an improvement regarding survival after myocardial infarction or stroke [9-11].

Therefore, the interest in novel antidiabetic therapies, such as sodium-glucose co-transporter-2 inhibitors (SGLT2i), has been growing. This class of drugs increases urinary glucose excretion independently of insulin secretion and causes weight loss, in addition to numerous other pleiotropic effects, resulted beyond anti-hyperglycemic efficacy [12]. Dapagliflozin, a SGLT2i, has been noted for its ability to reduce heart failure aggravation or cardiovascular-related death, regardless of the stage of diabetes [13].

The main aim of this study was to evaluate the possible baseline predictors associated with the remission of DD1 in patients with T2DM after one year of treatment with dapagliflozin.

\section{Material and Methods}

\subsection{Study Design and Patients}

In this prospective, observational study, 80 patients with T2DM attending scheduled medical visits at the Diabetes Clinic and Diabetes Outpatient of "Pius Brînzeu" Emergency Hospital were enrolled. Physicians prescribing diabetes treatment referred T2DM patients for this study before the initiation of dapagliflozin treatment. The ethical committee of the "Pius Brînzeu" Emergency County Hospital approved this research and it has met the requirements of the Helsinki Declaration. All participants agreed and signed a written informed consent before enrollment in the study.

T2DM patients over 18 years old, without cardiac valvulopathies or significant cardiac disease, without chronic viral hepatitis, with no alcohol misuse, with $\mathrm{HbA1c}>7 \%$, left ventricular ejection fraction $(\mathrm{LVEF})>40 \%$, and an estimated glomerular filtration rate (eGFR) $>60 \mathrm{~mL} / \mathrm{min} / 1.73 \mathrm{~m}^{2}$, met the eligibility criteria for participating in the study. Exclusion was based on the following criteria: LVEF < $40 \%$ and significant structural heart disease, ongoing or planned pregnancy, lactation, other than type 2 diabetes types, history of diabetic ketoacidosis, HbA1c $<7 \%$, eGFR $<60 \mathrm{~mL} / \mathrm{min} / 1.73 \mathrm{~m}^{2}$, normal-weight with a BMI $<25 \mathrm{~kg} / \mathrm{m}^{2}$, urinary tract infections that occurred during the study (possibly secondary to dapagliflozin treatment), or the patients refuse to participate in this clinical trial.

\subsection{Methods}

During the study, some patients were excluded due to intolerance or inefficacy of the treatment or at their request. We performed complex investigations in 45 patients enrolled in the study before starting daily treatment with $10 \mathrm{mg}$ of dapagliflozin. Dapagliflozin was add-on therapy to metformin, sulfonylureas or insulin as follows: $66.7 \%$ of the included patients had treatment with metformin, $11.1 \%$ had therapy with metformin and sulfonylureas, $11.1 \%$ had basal insulin and metformin, $8.9 \%$ had sulfonylureas, and $2.2 \%$ had intensive insulin therapy without metformin. None of the patients were treated with glucagon-like peptide-1 (GLP1) agonists in the study. We scheduled the follow-up medical examinations at 3, 6 and 12 months, respectively. 20\% (9/45) of patients needed an intensification of antidiabetic therapy as recommended by the international guidelines [14] with a molecule containing a combination of dapagliflozin and dipeptidyl-peptidase-4 inhibitors (DPP4i). At the six-month follow-up, patients successfully repeated the initial investigations, and at the one-year follow-up, they repeated only the cardiac ultrasound to screen for type 1 diastolic dysfunction (DD1) and body weight assessment. 
The assessments of clinical status, medical history, biological markers, and paraclinical investigations (cardiac ultrasound, transient elastography with controlled attenuation parameter (CAP), native computed tomography) are described in a previously published paper [15]. Type 1 diastolic dysfunction was defined as $\mathrm{E} / \mathrm{A}<1$ and $\mathrm{E} / \mathrm{e}^{\prime}>15$ [5]. We considered as study outcome DD1 remission at one-year medical examination. $73.3 \%$ of patients were initially diagnosed with DD1, and after a one-year treatment, only $24.4 \%$ remained with DD1 [15].

\subsection{Statistical Analysis}

We performed statistical analysis with GNU PSPP (Version 1.4.1, Software Foundation, Boston, MA, USA), MedCalc Statistical Software version 14.8.1 (MedCalc Software bvba, Ostend, Belgium), and Microsoft Office Excel (Professional Plus 2019 Edition). The distribution of numerical variables was tested with the Kolmogorov-Smirnov test. Continuous numerical variables are presented as mean \pm standard deviation, and numerical variables with nonparametric distribution are presented as median and interquartile range. The qualitative/nominal variables are presented as absolute frequencies in the class and relative frequencies (percentages of the total subgroup). To evaluate the significances of the differences, $t$-test (for normal distribution) and Mann-Whitney U-test (for non-normal distribution) were used. A $p$-value $<0.05$ was considered the threshold for statistical significance, and $95 \%$ populational confidence intervals were calculated.

To evaluate the impact of numerical and continuous variables on dichotomous events, we built univariate and multivariate logistic regression models. The variation of the dichotomous event's risk of occurrence was interpreted by the exponent means of B coefficient of the regression equation.

Linear regression analyses were performed to assess the impact of the variation of biological and paraclinical variables on the study outcomes after dapagliflozin therapy. The dependent variable was DD1 remission, and the independent variables, coded with 1 for positive, 0 for negative, were the following: $\mathrm{HbA} 1 \mathrm{c}$ target $<7 \%$; increased high-density lipoprotein cholesterol (HDLc); increased eGFR; decreased values of the following parameters: total cholesterol (CT), low-density lipoprotein cholesterol (LDLc), triglycerides (TG), urinary albumin to creatinine ratio (UACr), uric acid, L4 visceral abdominal fat volume, epi-cardiac fat volume, mediastinal fat thickness, and $\mathrm{HbA1c}$, respectively; improvement of liver fibrosis; improvement of hepatic steatosis at six-month follow-up; bodyweight at six-month follow-up. To evaluate the association of DD1 remission with the factors included in the analysis, measured on a continuous scale (such as patient's age, diabetes duration, $\Delta$ variables between baseline and 6-month follow-up for clinical, biological, and imaging parameters such as BMI, $\mathrm{HbA1c}$, fat volumes, CAP, liver stiffness), we built univariate, then multivariate logistic regression models, with potential predictors - the variables mentioned above, respectively, and DD1 remission as the outcome, after one year of treatment.

To evaluate the strength of the relationship between a potential etiological factor (the predominant type of fat tissue, gender) and the occurrence of the study outcome, we calculated the relative risk, odds ratio, and correlation coefficient, and the statistical significance of the association between the exposure factor, and the effect is described by the value of $p$ and the $95 \%$ confidence interval.

For evaluating the predictive power of predicting DD1 remission based on the $\Delta$ stiffness and the age of diabetes, we performed Receiver-Operating Characteristics (ROC) analyses. Predictive performance is described through sensitivity, specificity, and predictive values (positive and negative). The optimal threshold value of the predictor was considered equal to the Youden index. We compared the area under the model's ROC curve with the non-discriminant one to analyze the predictive capacity's statistical significance (the area under the ROC curve $=0.5$ ).

\section{Results}

In the study group, $53.3 \%(24 / 45)$ were men. The mean age of the patients was $56.9 \pm 9.7$ years, and the diabetes duration ranged from 0 to 24 years, with a median of 7 years. The mean age had no significant differences in relation to gender ( $57.8 \pm 8.5$ years in men and $55.9 \pm 11.1$ years in women). 
Men had a longer diabetes duration than women $(10 \pm 5.1$ years vs. $6.6 \pm 4.8$ years, $p=0.02)$. The quality of metabolic control, as evaluated by $\mathrm{HbA1c}$, was similarly improved after six months of treatment both in women $(\triangle \mathrm{HbA} 1 \mathrm{c}=1.2 \pm 2.7$ percentage points $)$ and in men $(\triangle \mathrm{HbA} 1 \mathrm{c}=1.3 \pm 2.6$ percentage points), $p=0.9$. The dynamics of clinical, biological, and imagistic parameters of the subjects included in this study are presented in Table 1.

Table 1. The dynamics of studied variables.

\begin{tabular}{|c|c|c|c|}
\hline Variable & Baseline & $\begin{array}{l}\text { At Six-Month } \\
\text { Follow-Up }\end{array}$ & $p$ \\
\hline Glycemia $(\mathrm{mg} / \mathrm{dL})^{\mathrm{b}}$ & $213.1 \pm 69.5$ & $152.8 \pm 35$ & $<0.001 *$ \\
\hline Total cholesterol $(\mathrm{mg} / \mathrm{dL})^{\mathrm{b}}$ & $197.1 \pm 61.2$ & $191.1 \pm 46.5$ & 0.07 \\
\hline Triglycerides $(\mathrm{mg} / \mathrm{dL})^{\text {a }}$ & $170(5 ; 887)$ & $150(58 ; 1397)$ & 0.4 \\
\hline LDLc (mg/dL) ${ }^{b}$ & $120.7 \pm 47.1$ & $107.4 \pm 39.4$ & 0.3 \\
\hline $\operatorname{HDLc}(\mathrm{mg} / \mathrm{dL})^{a}$ & $39(17 ; 89)$ & $42(19 ; 90)$ & $0.03 *$ \\
\hline women $b$ & $39.8 \pm 11.8$ & $45.1 \pm 12.4$ & 0.1 \\
\hline men $^{\mathrm{a}}$ & $39(17 ; 89)$ & $41.5(19 ; 90)$ & $0.03 *$ \\
\hline Uric acid $(\mathrm{mg} / \mathrm{dL})^{\mathrm{b}}$ & $4.9 \pm 1.2$ & $4.6 \pm 1.1$ & 0.1 \\
\hline $\mathrm{eGFR}\left(\mathrm{mL} / \mathrm{min} / 1.73 \mathrm{~m}^{2}\right)^{\mathrm{b}}$ & $86.1 \pm 14.4$ & $94.2 \pm 13.2$ & $0.007 *$ \\
\hline HbA1c $(\%)^{b}$ & $8.6 \pm 1.1$ & $7.9 \pm 1.2$ & $0.003 *$ \\
\hline $\mathrm{UACr}(\mathrm{mg} / \mathrm{g})^{\mathrm{a}}$ & $15.4(5.5 ; 471.1)$ & $16.7(1.3 ; 928.3)$ & 0.9 \\
\hline Weight $(\mathrm{kg})^{\mathrm{b}}$ & $99.4 \pm 4.7$ & $94.7 \pm 14.9$ & $0.0001 *$ \\
\hline women $b$ & $94.5 \pm 15.3$ & $90.1 \pm 15.7$ & $<0.0001 *$ \\
\hline men $\mathrm{b}$ & $103.6 \pm 16.3$ & $98.7 \pm 13.3$ & $<0.0001 *$ \\
\hline BMI $\left(\mathrm{kg} / \mathrm{m}^{2}\right)^{\mathrm{b}}$ & $34.9 \pm 4.7$ & $33.3 \pm 4.6$ & $<0.0001 *$ \\
\hline women $b$ & $36.6 \pm 5$ & $35 \pm 5.3$ & $0.0002 *$ \\
\hline men ${ }^{b}$ & $33.4 \pm 4$ & $31.9 \pm 3.5$ & $<0.0001$ * \\
\hline waist $(\mathrm{cm}) \mathrm{b}$ & $116 \pm 11.8$ & $114.3 \pm 11.5$ & $0.03 *$ \\
\hline women $b$ & $115.6 \pm 10.1$ & $115 \pm 11$ & 0.5 \\
\hline men ${ }^{b}$ & $116.2 \pm 13.2$ & $113.7 \pm 12.1$ & $0.02 *$ \\
\hline $\operatorname{AST}(\mathrm{u} / \mathrm{L})$ & $27(12 ; 80)$ & $21(9 ; 45)$ & $0.01 *$ \\
\hline $\operatorname{ALT}(\mathrm{u} / \mathrm{L})$ & $47(20 ; 174)$ & $34.5(21 ; 74)$ & $0.002 *$ \\
\hline Systolic BP (mmHg) & $142.3 \pm 21.5$ & $137.8 \pm 17$ & 0.2 \\
\hline Diastolic BP (mmHg) & $85(65 ; 125)$ & $85(70 ; 105)$ & 0.9 \\
\hline $\begin{array}{l}\text { The epicardial fat thickness on } \\
\text { echo cardiac (mm) b }\end{array}$ & $6 \pm 1.3$ & $4.2 \pm 1.4$ & $0.0001 *$ \\
\hline women ${ }^{b}$ & $6 \pm 1.3$ & $4 \pm 1$ & $<0.0001$ * \\
\hline men $^{b}$ & $6 \pm 1.4$ & $4.3 \pm 1.7$ & $0.0002 *$ \\
\hline EPI volume $\left(\mathrm{cm}^{3}\right)^{\mathrm{b}}$ & $37.6 \pm 16.3$ & $20.6 \pm 7.3$ & $<0.0001 *$ \\
\hline women $b$ & $35.8 \pm 17$ & $19.6 \pm 5$ & $0.0003 *$ \\
\hline men ${ }^{b}$ & $9.5 \pm 16.1$ & $21.4 \pm 8.8$ & $<0.0001$ * \\
\hline L4 visceral fat thickness $(\mathrm{mm})^{b}$ & $64 \pm 15.8$ & $65.4 \pm 14.4$ & 0.6 \\
\hline women $\mathrm{b}$ & $69.1 \pm 14.5$ & $68.7 \pm 13.9$ & 0.8 \\
\hline men ${ }^{b}$ & $61.1 \pm 17.1$ & $62.8 \pm 14.5$ & 0.3 \\
\hline L4 fat volume $\left(\mathrm{cm}^{3}\right)^{b}$ & $37.8 \pm 29.8$ & $41.9 \pm 18.5$ & 0.4 \\
\hline women $b$ & $35.5 \pm 27.6$ & $45.9 \pm 17.4$ & 0.07 \\
\hline men $b$ & $42.9 \pm 31.5$ & $38.2 \pm 19.1$ & 0.5 \\
\hline
\end{tabular}


Table 1. Cont.

\begin{tabular}{|c|c|c|c|}
\hline Variable & Baseline & $\begin{array}{l}\text { At Six-Month } \\
\text { Follow-Up }\end{array}$ & $p$ \\
\hline Mediastinal fat thickness $(\mathrm{mm})^{b}$ & $24.4 \pm 6.8$ & $27.8 \pm 6.9$ & $0.02 *$ \\
\hline women ${ }^{b}$ & $25 \pm 5.1$ & $26.5 \pm 6.5$ & 0.1 \\
\hline men ${ }^{b}$ & $25.8 \pm 7.6$ & $28.9 \pm 7.1$ & 0.1 \\
\hline $\mathrm{CAP}(\mathrm{dB} / \mathrm{m})^{\mathrm{a}}$ & $368(240 ; 400)$ & $310(190 ; 400)$ & 0.0003 * \\
\hline women $b$ & $362.6 \pm 31.7$ & $316.1 \pm 52$ & 0.001 * \\
\hline $\operatorname{men}^{\mathrm{a}}$ & $373(240 ; 400)$ & $310(190 ; 400)$ & $0.03 *$ \\
\hline Fibroscan (liver stiffness) (kPa) ${ }^{a}$ & $7.2(3.5 ; 43.8)$ & $6.7(3.3 ; 15.3)$ & 0.09 \\
\hline women ${ }^{a}$ & $7.4(3,5 ; 43.8)$ & $7.3(3.4 ; 15.3)$ & 0.3 \\
\hline men $^{a}$ & $6.8(3.9 ; 20)$ & $6.2(3.3 ; 12.1)$ & 0.1 \\
\hline
\end{tabular}

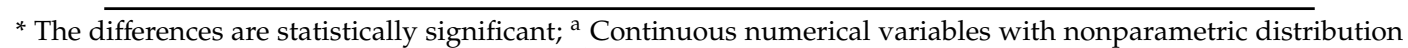
expressed as median and [interquartile range]; ${ }^{b}$ The results of the variables with normal distribution are expressed as mean \pm standard deviation; LDLc $=$ low density lipid cholesterol; HDLc $=$ high density lipid cholesterol; $\mathrm{eGFR}=$ estimated glomerular filtration rate; $\mathrm{HbA1}=$ glycated hemoglobin; $\mathrm{UACr}=$ urinary albumin to creatinine ratio; $\mathrm{BMI}=$ body mass index; $\mathrm{AST}=$ aspartate aminotransferase; $\mathrm{ALT}=$ alanine aminotransferase; $\mathrm{BP}=$ blood pressure; $\mathrm{EPI}=$ epicardial adipose tissue; $\mathrm{L} 4=$ the forth vertebrae; $\mathrm{CAP}=$ controlled attenuation parameter; Fibroscan $=$ liver stiffness score.

The patients who needed an intensification of antidiabetic therapy at 3-month follow-up with a molecule containing a combination of dapagliflozin and DPP4 inhibitors, which constituted $20 \%$ of the total subjects $(9 / 45,4$ women, and 5 men), had a mean age of $61.6 \pm 9.1$ years and a diabetes duration of $9 \pm 4.5$ years. The main characteristics in dynamics of this subgroup were similar to the initial group.

\subsection{Binary Regression Models}

In the univariate binary regression analysis, DD1 remission is associated with the improvement of liver fibrosis, the increase of eGFR, and the decrease of HbA1c.

In the multivariate binary regression model, the increase of eGFR and the decrease of $\mathrm{HbA} 1 \mathrm{c}$ were kept as significant associations with our outcome $(p=0.003,77.78 \%$ correctly classified cases; for each, $B$ coefficient was 2.07 , and the standard error 0.96 ).

The $\triangle \mathrm{HbA1c}$ between baseline and six-month measurements was significantly associated with the increase of the probability of DD1 remission $(p=0.03)$. The $\Delta \mathrm{BMI}$ between baseline and the one-year-evaluation reduces the chance of DD1 remission but not statistically significant $(p=0.06)$. Similarly, $\triangle$ GFR in the two evaluations indicated that for each decrease of eGFR by $1 \mathrm{~mL} / \mathrm{min} / 1.73 \mathrm{~m}^{2}$ the probability of DD1 remission decreases by $9 \%(p=0.02)$. The patients' age was not statistically significantly associated with DD1 dynamics $(p=0.3)$. On the same note, patients who had a long diabetes duration were at higher risk of diastolic dysfunction persistence for each year of disease duration $(p=0.01)$, so every year of diabetes will decrease the probability of DD1 remission by $19 \%$. The exponent means of B coefficient of the regression equations are listed in Table 2.

Table 2. Predictors associated with the remission of diastolic dysfunction (DD1).

\begin{tabular}{ccc}
\hline Variable & $\operatorname{Exp}(\beta)$ & $p$ \\
\hline$\Delta \mathrm{HbA} 1 \mathrm{c}(\%)^{* *}$ & 1.85 & $0.03^{*}$ \\
$\Delta \mathrm{BMI}\left(\mathrm{kg} / \mathrm{m}^{2}\right)^{* *}$ & 0.61 & 0.06 \\
$\Delta \mathrm{GFR}\left(\mathrm{mL} / \mathrm{min} / 1.73 \mathrm{~m}^{2}\right)^{* *}$ & 0.91 & $0.02^{*}$ \\
Age (years) ${ }^{* *}$ & 0.96 & 0.3 \\
Diabetes duration (years) ${ }^{* *}$ & 0.81 & $0.01^{*}$ \\
$\Delta$ liver stiffness $(\mathrm{kPa})^{* * *}$ & 1.24 & $0.04^{*}$ \\
$\Delta \mathrm{CAP}(\mathrm{dB} / \mathrm{m})^{* * *}$ & 0.99 & 0.4 \\
\hline
\end{tabular}

* The results are statistically significant; ${ }^{* *}$ Univariate regression models; ${ }^{* * *}$ Logistic regression models. 


\subsection{Logistic Regression Models}

According to the univariate logistic regression model (Table 2), we observed that the $\Delta$ liver stiffness score after six months of dapagliflozin is a statistically significant predictive factor $(p=0.04)$. The $\triangle \mathrm{CAP}$ was not significantly associated with DD1 remission $(p=0.4)$.

ROC curve analysis for $\Delta$ liver stiffness showed an area under the ROC curve $=0.726$, sensitivity $71.4 \%$, specificity $70 \%$, positive predictive values 81.5 and negative $45.5, p=0.02$ with Youden Index J $=0.41$ (Figure 1).

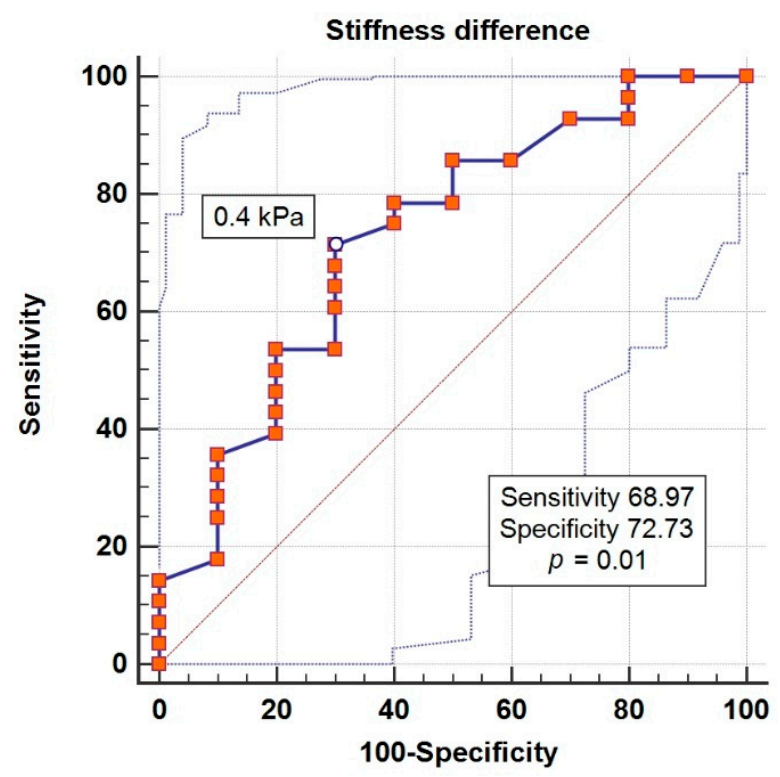

Figure 1. Graphical representation of the Receiver-Operating Characteristics (ROC) curve of the difference in liver stiffness for the prediction of diastolic dysfunction remission.

A diabetes duration $\leq 8$ years represents a statistically significant predictive factor for DD1 remission, with a sensitivity of $68.7 \%$ and specificity of $81.8 \%$, according to the ROC curve (area under the curve $0.788,91.6$ positive predictive values, and 47.3 negative predictive values, $p<0.0001$ ), as illustrated in Figure 2.

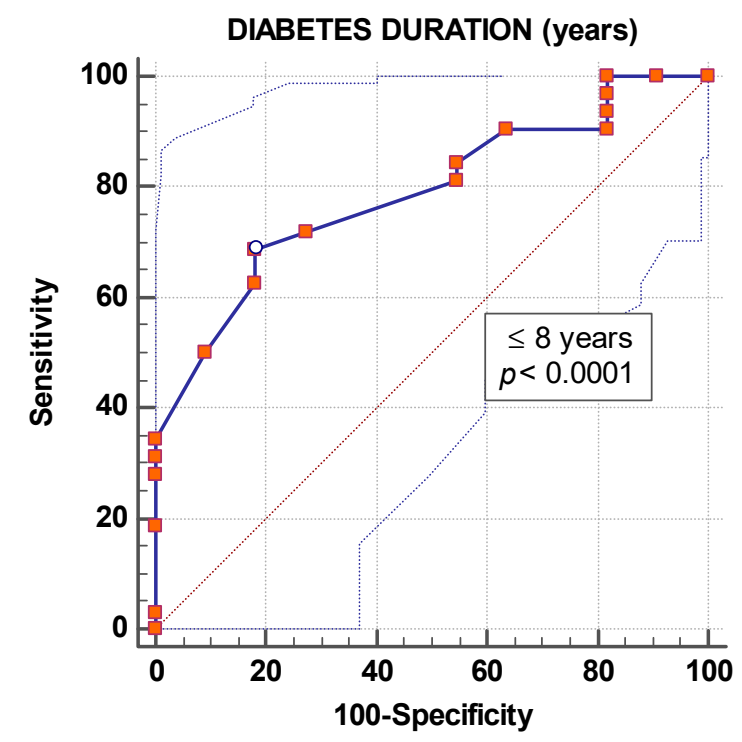

Figure 2. Graphical representation of the ROC curve of diabetes duration for the prediction of diastolic dysfunction remission. 


\subsection{Risk Analysis}

To analyze whether the predominant type of adipose tissue is a risk factor for the DD1 remission following one-year treatment with dapagliflozin, we used the following codes: patients with a subcutaneous/visceral fat ratio greater than 1 were coded with 0 , and the others with 1 ; the patients with remitted DD1 were coded with 1, and the others with 0 . Figure 3 illustrates the frequency of DD1 remission stratified by the predominant type of adipose tissue.

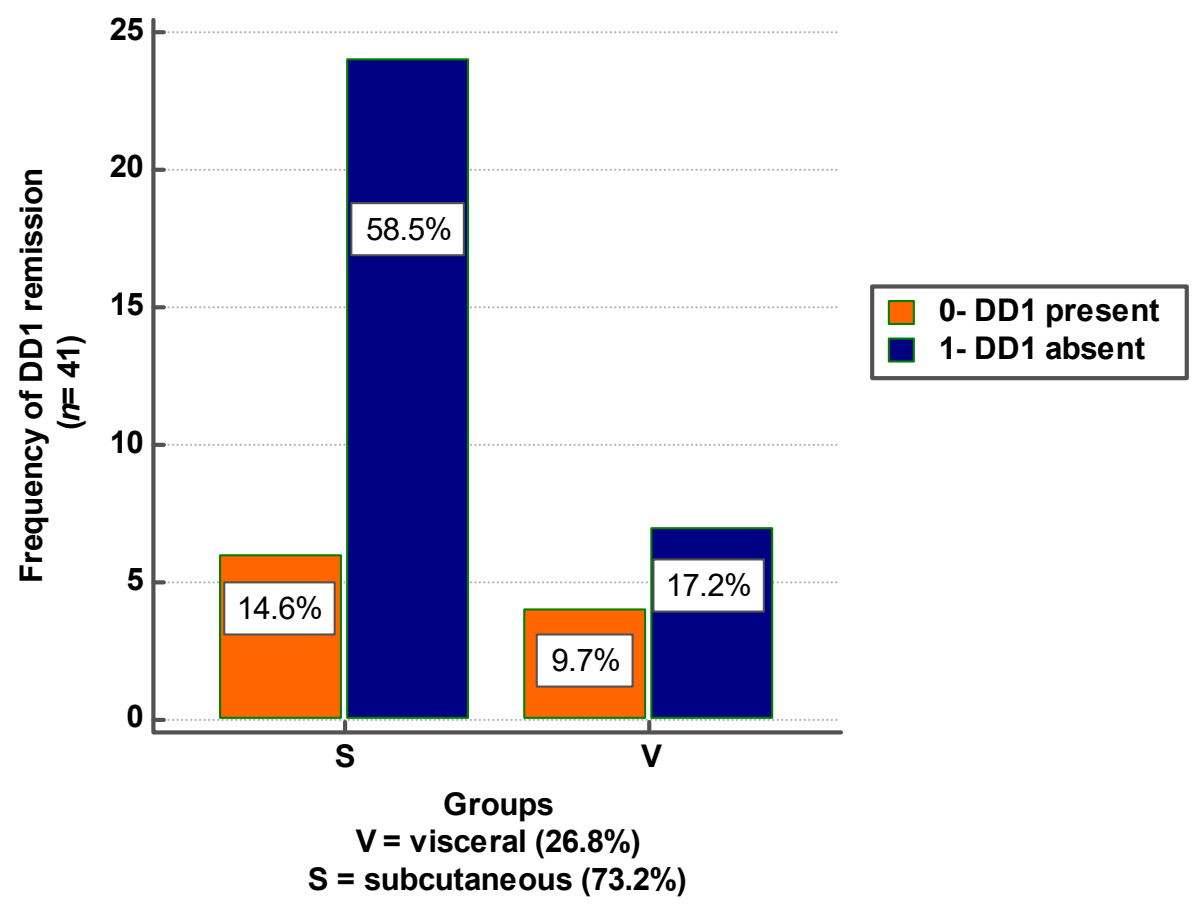

Figure 3. Frequency of diastolic dysfunction remission after one year of dapagliflozin, depending on the predominant type of adipose tissue.

We considered the exposure factor the predominant type of adipose tissue, and the expected result DD1 remission. The results were not statistically significant and are presented in Table 3.

Table 3. Risk analysis for DD1 remission depending on the predominant type of adipose tissue in study patients.

\begin{tabular}{ccccc}
\hline & \multicolumn{2}{c}{ Subcutaneous Adipose Tissue Predominance } & \multicolumn{2}{c}{ Visceral Adipose Tissue Predominance } \\
\cline { 2 - 5 } & At Six Months & At One Year & At Six Months & At One Year \\
\hline Relative risk & 0.41 & 1.25 & 2.4 & 0.79 \\
CI 95\% & $0.15-1.08$ & $0.77-2.03$ & $0.9-6.3$ & $0.49-1.28$ \\
statistic z & 1.791 & 0.932 & 1.7 & 0.93 \\
$p$ & 0.07 & 0.35 & 0.07 & 0.3 \\
Odds ratio & 0.27 & 2.28 & 3.61 & 0.43 \\
CI 95\% & $0.06-1.21$ & $0.5-10.44$ & $0.8-15.8$ & $0.09-1.99$ \\
statistic z & 1.698 & 0.932 & 1.6 & 1.066 \\
$p$ & 0.08 & 0.28 & 0.08 & 0.28 \\
\hline
\end{tabular}

$\mathrm{CI}=$ confidence interval.

To see if the patient's gender influenced the study outcome, we performed the risk analysis in dynamic, considering the female gender as the risk factor. At the first cardiac ultrasound, women had a relative risk $<1(\mathrm{RR}=0.42,95 \% \mathrm{CI} 0.13-1.40)$, without statistical significance. At one-year follow-up, the analysis indicated a relative risk of $>1(R R=1.26,95 \% C I 0.89-1.78)$, but it was not statistically significant. 


\section{Discussion}

According to the SHORTWAVE study, in a T2DM population with no documented cardiovascular disease and no signs of ischemia in stress test, left ventricle dysfunction has a high prevalence, up to $68 \%$ [16]. In previous studies, diastolic dysfunction has been associated with aging, a long duration of diabetes, increased blood pressure, and interventricular septal thickness, dyslipidemia, and a moderately high $\mathrm{HbA1c}$ [17]. Also, there is evidence that the epi-cardiac adipose tissue associated with insulin resistance and coronary artery disease alters the diastolic function by secreting some pro-inflammatory cytokines [18].

In T2DM patients, the prevalence of diastolic dysfunction varies from $47 \%$ to $71 \%$ because of different echocardiographic criteria used for screening, patients' cardiac function, and different diastolic dysfunction grades [19-22]. Similar to other studies, in our research $73 \%$ of patients had diastolic dysfunction. However, our screening was specifically addressed for DD1, which we consider of scientific interest because it represents an alteration in the left ventricle's active relaxation without myocardial structural damage. The presence of myocardial structural changes, atrial fibrillation, or significant valvulopathies were exclusion criteria in this study. Our experiment showed an improvement in the diastolic function after six months of dapagliflozin therapy, but especially after 48 weeks of treatment. From an initial percentage of $73 \%$, at the final cardiac ultrasound evaluation, DD1 was present only in $24.4 \%$ of patients. During the study, patients who required intensification of diabetes treatment through the association of a SGLT2i and a DPP4i had the most significant benefit regarding DD1 remission. In these patients, DD1 remission was statistically significant at a $100 \%$ rate, while in the group of patients treated only with SGLT2i, the remission rate was 58\% [15]. This diastolic improvement may be attributed to the improvement of cardiac output, reduced plasma volume, followed by SGLT2 inhibition $[23,24]$.

In a study by Matsutani et al., screening for diastolic dysfunction was performed on 34 patients with T2DM before and after three months of therapy with canagliflozin; changes in the septal E/e' ratio was observed. Of all potential predictive factors analyzed with the target of decreasing E/e', only changes in hemoglobin was associated independently in a multivariate regression model. It is important to note that about $32 \%$ of patients evaluated by Matsutani et al. had cardiovascular disease [25].

In our study, the epicardial fat volume and the left atrium volume were associated with the mitral E/A ratio correction. Verma et al. reported similar effects of empagliflozin regarding cardiac structure and heart function in a group of 10 patients with known cardiovascular disease for a short period of 3-month follow-up. They noted a significant reduction in the left ventricle mass index and an improvement in diastolic function, evaluated by $\mathrm{e}^{\prime}$ wave [26].

In the regression models, we analyzed the extent to which the dynamics of the values of all the reviewed markers influenced our primary end-point-DD1 remission. In univariate binary logistic regression models, the improvement of liver stiffness, the increase in eGFR, and the decrease of HbA1c after six months of therapy with dapagliflozin were associated independently with the DD1 remission. The magnitude of $\mathrm{HbA1c}$ decrease after SGLT2i treatment could explain the DD1 remission. Also, it appears that the deterioration of kidney function in patients treated with dapagliflozin could be associated with DD1 persistence. For each decrease of eGFR by $1 \mathrm{~mL} / \mathrm{min}$, the risk of DD1 persistence will increase by $9 \%$. In logistic regression analysis, the difference in stiffness score was a predictive factor for DD1 remission, and a reduction of $0.4 \mathrm{kPa}$ in stiffness score could increase the probability of DD1 remission by $24 \%$. After assessing the relationship between potential predictive factors and their simultaneous impact on the improvement of diastolic function, in the multivariate analysis only the stiffness difference after SGLT2i remained a valid, statistically significant predictive factor.

Although the mechanisms underlying these associations are unclear, the present study findings suggest the anti-inflammatory effect of dapagliflozin. In experimental studies, dapagliflozin has been shown to slow glomerulosclerosis and liver fibrosis progression by reducing tissue inflammation markers and oxidative stress induced by chronic hyperglycemia [27]. 
Subjects' age or gender did not influence the dynamics of DD1. On the contrary, every year of diabetes duration decreased the chance of DD1 remission by $19 \%$. A threshold value of $\leq 8$ years of diabetes duration was a predictive factor for DD1 remission in the ROC analysis. This finding suggests the importance of initiating treatment with dapagliflozin as early as possible.

Studies have concluded that obesity is another significant cause of HF with preserved ejection fraction, hypertension, and DM [28]. Ichikawa et al. demonstrated that abdominal visceral adiposity, measured by computed tomography, was an independent determinant of the parameters of left ventricular diastolic function (E/A, $\mathrm{e}^{\prime}$, and $\left.\mathrm{E} / \mathrm{e}^{\prime}\right)$ in 148 asymptomatic $\mathrm{DM}$ patients with preserved LVEF [29]. Our study results show that DD1 remission was not due to patients' weight loss. Neither body weight nor BMI was associated with our objective. It is known that obesity may be due to an excess of subcutaneous or visceral adipose tissue. In our study, most patients had subcutaneous excess fat tissue. The predominant type of adipose tissue in these patients did not affect our outcome.

Previous studies have reported an association between diastolic dysfunction and liver stiffness [30] that may be explained by the altered hemodynamics secondary to progressive cardiac fibrosis and diastolic dysfunction which in turn promotes the progression in liver stiffness and fibrosis [31]; liver fibrosis activates cardiac fibrosis as described in a study about 'cirrhotic cardiomyopathy', a pathology which also includes diastolic dysfunction [32]; moreover, it has been proved that serum biomarkers of fibrosis including matrix metalloproteinases and tissue inhibitor of metalloproteinases are elevated in both cardiac and hepatic fibrosis [33]. Future studies should aim investigate the pathophysiological mechanisms behind the association of diastolic dysfunction and liver stiffness.

\section{Study Limitations}

This study assessed a small number of patients without a placebo-controlled group after a short period of dapagliflozin therapy; however, the sample size estimation pointed to an appropriate sample size for the study's primary end-point.

\section{Conclusions}

Although the mechanisms by which this molecule improves diastolic dysfunction are not fully understood, this research showed significant associations between the remission of DD1 and improvement of liver stiffness, increase of eGFR, increase of $\mathrm{HbA} 1 \mathrm{c}$, and EPI volume, regardless of age, BMI, or abdominal visceral adiposity. A difference of more than $0.4 \mathrm{kPa}$ in the stiffness score predicts DD1 remission with a sensitivity of $71 \%$ and specificity of $70 \%$.

A longer diabetes duration is associated with a decrease in the likelihood of DD1 duration. We can predict the remission of DD1 in T2DM patients with a diabetes duration of $\leq 8$ years treated for one year with dapagliflozin with a sensitivity of $68.7 \%$ and specificity of $81.8 \%$.

Author Contributions: Conceptualization, A.B. and B.T.; methodology, A.B., L.V., A.S.; software, D.C., L.V.; validation, A.B., R.T. and B.T.; formal analysis, A.B., A.A., L.D., B.T. and R.T.; investigation, A.B., L.V. and D.C.; resources, A.B., A.A., R.T., L.D., B.T. and A.S.; data curation, A.B.; writing-original draft preparation, A.B., B.T.; writing-review and editing, A.B., A.A., R.T., L.D., B.T., L.V., D.C. and A.S.; visualization, R.T., B.T. and A.A.; supervision, R.T., B.T., A.A. and A.S.; project administration, A.B. All authors have read and agreed to the published version of the manuscript.

Funding: This research received no external funding.

Acknowledgments: The authors gratefully acknowledge the professionals from the Diabetes Center of the "Pius Brînzeu" Emergency Hospital Timisoara, Romania, for their administrative and technical support.

Conflicts of Interest: The authors declare no conflict of interest.

\section{References}

1. Benjamin, E.J.; Virani, S.S.; Callaway, C.W.; Chamberlain, A.M.; Chang, A.R.; Cheng, S.; Chiuve, S.E.; Cushman, M.; Delling, F.N.; Deo, R.; et al. Heart Disease and Stroke Statistics-2018 Update: A Report from the American Heart Association. Circulation 2018, 137, e67-e492. [CrossRef] [PubMed] 
2. Vazquez-Benitez, G.; Desai, J.R.; Xu, S.; Goodrich, G.K.; Schroeder, E.B.; Nichols, G.A.; Segal, J.; Butler, M.G.; Karter, A.J.; Steiner, J.F.; et al. Preventable Major Cardiovascular Events Associated with Uncontrolled Glucose, Blood Pressure, and Lipids and Active Smoking in Adults with Diabetes with and without Cardiovascular Disease: A Contemporary Analysis. Diabetes Care 2015, 38, 905-912. [CrossRef] [PubMed]

3. Kosmala, W.; Colonna, P.; Przewlocka-Kosmala, M.; Mazurek, W. Right ventricular dysfunction in asymptomatic diabetic patients. Diabetes Care 2004, 27, 2736-2738. [CrossRef] [PubMed]

4. Galderisi, M. Diagnosis and Management of Left Ventricular Diastolic Dysfunction in the Hypertensive Patient. Am. J. Hypertens. 2011, 24, 507-517. [CrossRef] [PubMed]

5. Nishimura, R.A.; Tajik, A. Evaluation of Diastolic Filling of Left Ventricle in Health and Disease: Doppler Echocardiography Is the Clinician's Rosetta Stone. J. Am. Coll. Cardiol. 1997, 30, 8-18. [CrossRef]

6. Andersen, O.S.; Smiseth, O.A.; Dokainish, H.; Abudiab, M.M.; Schutt, R.C.; Kumar, A.; Sato, K.; Harb, S.; Gude, E.; Remme, E.W.; et al. Estimating Left Ventricular Filling Pressure by Echocardiography. J. Am. Coll. Cardiol. 2017, 69, 1937-1948. [CrossRef]

7. Ponikowski, P.; Voors, A.A.; Anker, S.D.; Bueno, H.; Cleland, J.G.F.; Coats, A.J.S.; Falk, V.; González-Juanatey, J.R.; Harjola, V.-P.; Jankowska, E.A.; et al. 2016 ESC Guidelines for the diagnosis and treatment of acute and chronic heart failure: The Task Force for the diagnosis and treatment of acute and chronic heart failure of the European Society of Cardiology (ESC) Developed with the special contribution of the Heart Failure Association (HFA) of the ESC. Eur. Heart J. 2016, 37, 2129-2200.

8. Blonde, L. Benefits and Risks for Intensive Glycemic Control in Patients with Diabetes Mellitus. Am. J. Med. Sci. 2012, 343, 17-20. [CrossRef]

9. Turnbull, F.M.; Abraira, C.; Anderson, R.J.; Byington, R.P.; Chalmers, J.P.; Duckworth, W.C.; Evans, G.W.; Gerstein, H.C.; Holman, R.R.; Moritz, T.E.; et al. Intensive glucose control and macrovascular outcomes in type 2 diabetes. Diabetology 2009, 52, 2288-2298. [CrossRef]

10. Mattila, T.K.; De Boer, A. Influence of Intensive versus Conventional Glucose Control on Microvascular and Macrovascular Complications in Type 1 and 2 Diabetes Mellitus. Drugs 2010, 70, 2229-2245. [CrossRef]

11. Ray, K.K.; Seshasai, S.R.K.; Wijesuriya, S.; Sivakumaran, R.; Nethercott, S.; Preiss, D.; Erqou, S.; Sattar, N. Effect of intensive control of glucose on cardiovascular outcomes and death in patients with diabetes mellitus: A meta-analysis of randomised controlled trials. Lancet 2009, 373, 1765-1772. [CrossRef]

12. Scheen, A.J. Pharmacokinetic and Pharmacodynamic Profile of Empagliflozin, a Sodium Glucose Co-Transporter 2 Inhibitor. Clin. Pharmacokinet. 2014, 53, 213-225. [CrossRef] [PubMed]

13. McMurray, J.J.; Solomon, S.D.; Inzucchi, S.E.; Køber, L.; Kosiborod, M.N.; Martinez, F.A.; Ponikowski, P.; Sabatine, M.S.; Anand, I.S.; Bělohlávek, J.; et al. Dapagliflozin in Patients with Heart Failure and Reduced Ejection Fraction. New Engl. J. Med. 2019, 381, 1995-2008. [CrossRef] [PubMed]

14. Davies, M.J.; D’Alessio, D.A.; Fradkin, J.; Kernan, W.N.; Mathieu, C.; Mingrone, G. Management of hyperglycaemia in type 2 diabetes, 2018. A consensus report by the American Diabetes Association (ADA) and the European Association for the Study of Diabetes (EASD). Diabetologia 2018, 61, 2461-2498. [CrossRef]

15. Braha, A.; Timar, B.; Diaconu, L.; Lupusoru, R.; Vasiluta, L.; Sima, A.; Vlad, A.; Munteanu, M.; Albai, A.; Cipu, D.; et al. Dynamics of Epicardiac Fat and Heart Function in Type 2 Diabetic Patients Initiated with SGLT-2 Inhibitors. Diabetes Metab. Syndr. Obes. Targets Ther. 2019, 12, 2559-2566. [CrossRef]

16. Faden, G.; Faganello, G.; De Feo, S.; Berlinghieri, N.; Tarantini, L.; Di Lenarda, A.; Faggiano, P.; Cioffi, G. The increasing detection of asymptomatic left ventricular dysfunction in patients with type 2 diabetes mellitus without overt cardiac disease: Data from the SHORTWAVE study. Diabetes Res. Clin. Pr. 2013, 101, 309-316. [CrossRef]

17. Celentano, A.; Vaccaro, O.; Tammaro, P.; Galderisi, M.; Crivaro, M.; Oliviero, M.; Imperatore, G.; Palmieri, V.; Iovino, V.; Riccardi, G.; et al. Early abnormalities of cardiac function in non-insulin-dependent diabetes mellitus and impaired glucose tolerance. Am. J. Cardiol. 1995, 76, 1173-1176. [CrossRef]

18. Ferrara, D.; Montecucco, F.; Dallegri, F.; Carbone, F. Impact of different ectopic fat depots on cardiovascular and metabolic diseases. J. Cell. Physiol. 2019, 234, 21630-21641. [CrossRef]

19. Exiara, T.; Konstantis, A.; Papazoglou, L.; Kouroupi, M.; Kalpaka, A.; Mporgi, L.; Risggits, A.; Filippidou, E.; Terzi, S.; Papanastasiou, S. LEFT VENTRICULAR DIASTOLIC DYSFUNCTION IN DIABETES MELLITUS TYPE 2: PP.17.147. J. Hypertens. 2010, 28, e294. [CrossRef]

20. Patil, V.C.; Shah, K.B.; Vasani, J.D.; Shetty, P.; Patil, H.V. Diastolic dysfunction in asymptomatic type 2 diabetes mellitus with normal systolic function. J. Cardiovasc. Dis. Res. 2011, 2, 213-222. [CrossRef] 
21. Shrestha, N.R.; Sharma, S.; Karki, P.; Shrestha, N.K.; Acharya, P. Echocardiographic evaluation of diastolic function in asymptomatic type 2 diabetes. J. Nepal. Med. Assoc. 2009, 48, 20-23. [CrossRef]

22. Ernande, L.; Bergerot, C.; Rietzschel, E.-R.; De Buyzere, M.L.; Thibault, H.; PignonBlanc, P.G.; Croisille, P.; Ovize, M.; Groisne, L.; Moulin, P.; et al. Diastolic Dysfunction in Patients with Type 2 Diabetes Mellitus: Is It Really the First Marker of Diabetic Cardiomyopathy? J. Am. Soc. Echocardiogr. 2011, 24, 1268-1275. [CrossRef] [PubMed]

23. Pham, S.V.; Chilton, R.J. EMPA-REG Outcome: The Cardiologist's Point of View. Am. J. Cardiol. 2017, 120, S53-S58. [CrossRef] [PubMed]

24. Rajasekeran, H.; Lytvyn, Y.; Cherney, D.Z. Sodium-glucose cotransporter 2 inhibition and cardiovascular risk reduction in patients with type 2 diabetes: The emerging role of natriuresis. Kidney Int. 2016, 89, 524-526. [CrossRef]

25. Matsutani, D.; Sakamoto, M.; Kayama, Y.; Takeda, N.; Horiuchi, R.; Utsunomiya, K. Effect of canagliflozin on left ventricular diastolic function in patients with type 2 diabetes. Cardiovasc. Diabetol. 2018, 17, 73. [CrossRef]

26. Verma, S.; Mazer, C.D.; Yan, A.T.; Mason, T.; Garg, V.; Teoh, H.; Goodman, S.G. Effect of Empagliflozin on Left Ventricular Mass in Patients with Type 2 Diabetes and Coronary Artery Disease: The EMPA-HEART CardioLink-6 Randomized Clinical Trial. Circulation 2019, 140, 1693-1702. [CrossRef]

27. Wang, D.; Luo, Y.; Wang, X.; Orlicky, D.J.; Myakala, K.; Yang, P.-Y.; Levi, M. The Sodium-Glucose Cotransporter 2 Inhibitor Dapagliflozin Prevents Renal and Liver Disease in Western Diet Induced Obesity Mice. Int. J. Mol. Sci. 2018, 19, 137. [CrossRef]

28. Haass, M.; Kitzman, D.W.; Anand, I.S.; Miller, A.; Zile, M.R.; Massie, B.M.; Carson, P.E. Body Mass Index and Adverse Cardiovascular Outcomes in Heart Failure Patients with Preserved Ejection Fraction. Circ. Hear. Fail. 2011, 4, 324-331. [CrossRef]

29. Ichikawa, R.; Daimon, M.; Miyazaki, T.; Kawata, T.; Miyazaki, S.; Maruyama, M.; Chiang, S.-J.; Suzuki, H.; Ito, C.; Sato, F.; et al. Influencing factors on cardiac structure and function beyond glycemic control in patients with type 2 diabetes mellitus. Cardiovasc. Diabetol. 2013, 12, 38. [CrossRef]

30. Alsaied, T.; Moore, R.A.; Lang, S.M.; Truong, V.; Lubert, A.M.; Veldtman, G.R.; Averin, K.; Dillman, J.R.; Trout, A.T.; Mazur, W.; et al. Myocardial fibrosis, diastolic dysfunction and elevated liver stiffness in the Fontan circulation. Open Hear. 2020, 7, e001434. [CrossRef]

31. Wu, F.M.; Opotowsky, A.R.; Raza, R.; Harney, S.; Ukomadu, C.; Landzberg, M.J.; Valente, A.M.; Breitbart, R.E.; Singh, M.N.; Gauvreau, K.; et al. Transient Elastography May Identify Fontan Patients with Unfavorable Hemodynamics and Advanced Hepatic Fibrosis. Congenit. Hear. Dis. 2014, 9, 438-447. [CrossRef] [PubMed]

32. Chayanupatkul, M.; Liangpunsakul, S. Cirrhotic cardiomyopathy: Review of pathophysiology and treatment. Hepatol. Int. 2014, 8, 308-315. [CrossRef] [PubMed]

33. Roeb, E. Matrix metalloproteinases and liver fibrosis (translational aspects). Matrix Biol. 2018, 69, 463-473. [CrossRef] [PubMed]

Publisher's Note: MDPI stays neutral with regard to jurisdictional claims in published maps and institutional affiliations.

(C) 2020 by the authors. Licensee MDPI, Basel, Switzerland. This article is an open access article distributed under the terms and conditions of the Creative Commons Attribution (CC BY) license (http://creativecommons.org/licenses/by/4.0/). 